\title{
Risk Reduction Strategies in BRCA Patients: An Indian Perspective
}

Although it is thought that up to one-third of the cases of breast cancer may harbor a familial trait, various studies have shown that the incidence of BRCA positivity in Indian breast cancer patients may range from $9 \%$ to $25 \%{ }^{[1]}$ It is difficult to get an accurate estimate of the prevalence of genetic mutations in India because unlike the Western world, the testing for genetic mutations is infrequently done in Indian patients. It can be inferred from clinical practice trends that an increasing number of urban patients are opting to be tested for genetic mutations because of the downward trend of the cost of these investigations. It is a well-established fact that BRCA mutated patients are at a higher risk for developing breast and ovarian cancer and hence require some kind of special attention for risk reduction either by interventional or noninterventional means. The various methods available for risk reduction include chemoprophylaxis, intensive surveillance and screening, and risk-reduction surgery or radiotherapy. These methods can be used either singly or in combination.

The NCCN guidelines mention the role of intensive and early screening of patients with genetic mutations. It is interesting to note that Category I evidence is assigned to the use of tamoxifen or raloxifene as chemoprophylaxis in the NCCN guidelines. ${ }^{[2]}$ The NSABP p-1 study, which showed the efficacy of tamoxifen in reducing the risk of breast cancer in high-risk individuals across all age groups, was the basis of this recommendation. ${ }^{[3]}$ In spite of robust evidence supporting the role of these Selective Estrogen Receptor Modifiers (SERMs), we find that more emphasis is laid on surgical methods for risk reduction. This is probably related to the recurrent cost of drugs, possibly poor patient compliance and rare but occasional potentially serious side effects such as thromboembolic phenomenon.

It is not easy to make a choice of appropriate therapy or intervention in such situations. Clinical management of patients at an increased risk for breast cancer requires consideration of risk, patient preference, and quality of life. ${ }^{[4]}$ The decision to undergo surgical risk reduction or to continue with intensified surveillance depends on several factors such as age, family history of malignancy, and previous surgery. ${ }^{[5]}$ There are three specific scenarios where risk reduction should be considered.

1. Patients diagnosed with breast cancer and on further investigation found to have BRCA1 and/or BRCA2 positivity. The risk reduction in such patients would be with regard to the opposite breast and ovary

2. Patients diagnosed with ovarian cancer with BRCA positivity

3. First-degree relatives of patients in whom BRCA mutation is discovered.
Intensive surveillance (frequent magnetic resonance imaging and/or mammography), chemoprevention (SERMs), and prophylactic risk-reduction surgery (salpingo-oophorectomy and mastectomy with reconstruction) are the options available for these patients with an increased risk. About $50 \%$ of the women diagnosed with BRCA mutation with or without cancer choose to undergo prophylactic risk reduction surgery in the form of bilateral mastectomy with reconstruction and bilateral salpingo-oophorectomy. These are the patients who have a high degree of anxiety toward the diagnosis of cancer and stand by their decision despite the perceived change in body image it brings about. The other half of patients who choose to undergo intensified surveillance are more concerned about their body image and hence defer risk reduction surgery. ${ }^{[6]}$

There are small studies reported where prophylactic radiotherapy has been successfully implemented as a risk reduction strategy in BRCA mutated patients. In patients with BRCA mutation who have already developed unilateral breast cancer, additional prophylactic radiotherapy to the opposite breast seems to confer a protective effect against the development of malignancy. ${ }^{[7]}$ Although long-term effects and consequences of radiotherapy continue to be of concern, this modality presents as a middle path for anxious patients who are unwilling to undergo surgery due to fear of altered body image, but at the same time want to reduce the risk of cancer in future.

There is a paucity of comparative data between different risk reduction strategies due to the small number of patients and large period required for the accumulation of events necessary for obtaining statistically significant results. Different centers in India are generating their own data. An independent observation as far as Indian patients are concerned is that most of them would prefer to go for nonsurgical interventions for risk reduction, as far as possible. This decision may be because of economic reasons as well as because of fear of being ostracized by society. Although it is obvious that prevention is better than early detection, an astute clinician would take this opportunity to make the person aware about potential measures for the early detection of malignancy, if it develops, thereby seizing the chance for early therapeutic intervention which would be beneficial in ensuring better overall survival. From a surgeon's perspective, it seems prudent that one should educate the concerned individuals about the benefits of risk reduction surgery but ultimately leave the choice to the patient and the family.

Amit S Parasnis

Department of Surgical Oncology, Deenanath Mangeshkar Hospital, Pune, Maharashtra, India 


\begin{abstract}
Address for correspondence:
Dr. Amit S Parasnis,

Department of Surgical Oncology, Deenanath Mangeshkar Hospital, Erandawane, Pune, Maharashtra, India.

E-mail: amitparasnis@gmail.com
\end{abstract}

Submitted: 27-May-2019

Accepted in Revised Form: 30-May-2019

Published: 04-Dec-2019

\section{References}

1. Parikh PM, Wadhwa J, Minhas S, Gupta A, Mittal S, Ranjan S, et al. Practical consensus recommendation on when to do BRCA testing. South Asian J Cancer 2018;7:106-9.

2. NCCN Clinical Practice Guidelines, Breast Cancer Risk Reduction. Version 1. 2019. p. MS-7, MS-8.

3. Fisher B, Costantino JP, Wickerham DL, Redmond CK, Kavanah M, Cronin WM, et al. Tamoxifen for prevention of breast cancer: Report of the national surgical adjuvant breast and bowel project P-1 study. J Natl Cancer Inst 1998;90:1371-88.

4. Ludwig KK, Neuner J, Butler A, Geurts JL, Kong AL. Risk reduction and survival benefit of prophylactic surgery in BRCA mutation carriers, a systematic review. Am J Surg 2016;212:660-9.

5. Johns D, Agarwal J, Anderson L, Ying J, Kohlmann W. Breast cancer risk reduction decisions of the BRCA-positive patient: An observational study at a single institution. J Womens
Health (Larchmt) 2017;26:702-6.

6. Croshaw RL, Marshall ML, Williams TL, Erb KM, Julian TB. Clinical study prophylactic and therapeutic breast conservation in BRCA1/2 mutation carriers. Int J Breast Cancer 2011;36:481563.

7. Evron E, Ben-David AM, Goldberg H, Fried G, Kaufman B, Catane $\mathrm{R}$, et al. Prophylactic irradiation to the contralateral breast for BRCA mutation carriers with early-stage breast cancer. Ann Oncol 2019;30:412-7.

This is an open access journal, and articles are distributed under the terms of the Creative Commons Attribution-NonCommercial-ShareAlike 4.0 License, which allows others to remix, tweak, and build upon the work non-commercially, as long as appropriate credit is given and the new creations are licensed under the identical terms.

\begin{tabular}{|l|l|}
\hline \multicolumn{2}{|c|}{ Access this article online } \\
\hline Quick Response Code: & Website: \\
\hline & www.ijmpo.org \\
\cline { 2 - 2 } & DOI: \\
\hline
\end{tabular}

How to cite this article: Parasnis AS. Risk reduction strategies in BRCA patients: An Indian perspective. Indian J Med Paediatr Oncol 2019;40:319-20. 